\title{
UTILIZAÇÃO DE RESÍDUOS DE CORPOS DE PROVA DE CONCRETO PARA FABRICAÇÃO DE PAVIMENTAÇÃO INTERTRAVADA
}

\section{USE OF WASTES OF CONCRETE SAMPLES FOR MANUFACTURE OF INTERLOCKING PAVEMENT}

Recebido em: 15/10/2018. Aceito em: 19/11/2018.
Rafael Amancio Carvalho' Ana Carolina Zoqueti Moraes ${ }^{2}$

Bruna Rehder Mizasse ${ }^{3}$

Marcolino Fernandes Neto 4

\section{RESUMO}

O presente trabalho avalia a viabilidade da produção de pisos intertravados reciclados, utilizando-se agregados provenientes de resíduos de corpos de prova de concreto descartados após teste de resistência à compressão em substituição aos agregados naturais. Foi realizada uma comparação entre pisos intertravados produzidos com agregados convencionais e reciclados, sendo estes com substituição parcial e total de agregados graúdos e miúdos, nas proporções de 20\%, 40\%, 60\%, 80\% e 100\%. Constatou-se que a solicitação para resistência à compressão e absorção de água foram atingidas após os 28 dias de cura por imersão, e, também, que houve ganhos econômicos e ambientais através do uso do agregado reciclado. Assim, analisando os quesitos técnicos, ambientais e econômicos constatou-se que o melhor índice de substituição é o de 100\% de agregado reciclado, apresentando valores de resistência de 38,2 MPa para agregados miúdos e 37,7 MPa para agregados graúdos.

Palavras-chave: Agregado reciclado. Resíduo corpo de prova. Pavimento intertravado.

\footnotetext{
1 Graduando em Engenharia Civil pelo Centro Universitário das Faculdades Associadas de Ensino (UNIFAE). E-mail: rafa-carvalho11@live.com

2 Graduanda em Engenharia Civil pelo Centro Universitário das Faculdades Associadas de Ensino (UNIFAE). E-mail: anzmoraes@gmail.com

3 Graduanda em Engenharia Civil pelo Centro Universitário das Faculdades Associadas de Ensino (UNIFAE). E-mail: brunarm2011@gmail.com

4 Doutor em Engenharia Mecânica pela Universidade Estadual de Campinas (UNICAMP). Docente do Centro Universitário das Faculdades Associadas de Ensino (UNIFAE). E-mail: marcolino@fae.br
} 


\section{ABSTRACT}

The present work evaluates the feasibility of the recycled interlocking floors production, replacing the natural aggregates with waste of concrete samples aggregates, discarded after compressive tests. A comparison was made between interlocking floors produced with conventional and recycled aggregates, with partial and total replacement of large and small aggregates in the proportions of $20 \%, 40 \%$, $60 \%, 80 \%$ and $100 \%$. It was found that the request for resistance to compression and water absorption were reached after 28 days of curing by immersion, and also that the use of recycle aggregate brought economic and environmental gains. Therefore, by analyzing the technical, environmental and economic requirements, it was verified that the best substitution index is $100 \%$ recycled aggregate, presenting resistance values of 38.2 MPa for small aggregates and 37.7 MPa for large aggregates.

Keywords: Recycled aggregates. Waste of concrete samples. Interlocking floors.

\section{INTRODUÇÃO}

A construção civil é umas das atividades de origem mais antiga, apresentando através de seu exercício a geração de resíduos de diversas naturezas. Durante as últimas décadas, houve uma urbanização acelerada, bem como a expansão das cidades, assim, acontecendo o crescimento do setor construtivo, e, por consequência, gerando uma grande atenção voltada aos impactos ambientais, visto que este setor é responsável pelo maior consumo de recursos naturais do planeta. (BRASILEIRO; MATOS, 2015).

Assim, devido à preocupação gerada pelo setor construtivo, a fiscalização passou a se tornar efetiva por intermédio dos órgãos ambientais com a implantação de mecanismos pelo CONAMA (2002), tendo como propósito a rescisão dos problemas gerados pelos RCD (Resíduos da Construção e Demolição), definindo responsabilidades e deveres, e decretando aos geradores a obrigatoriedade da redução, reutilização e reciclagem dos resíduos. Quanto as ferramentas dispostas pelo órgão, pode-se citar a Lei Federal No 12.305 (2010), que instituiu a Política Nacional de Resíduos Sólidos, que tem como objetivo operar o correto gerenciamento dos resíduos produzidos nas diversas áreas da construção, indústrias e serviços.

Apesar dos RCD serem considerados de baixo risco, possuem como impacto o imenso volume produzido. Segundo ABRECON (2016), o Brasil produz cerca de 84 milhões de metros cúbicos de resíduos de construção e demolição por ano. Dessa forma, como resultado da grande geração de resíduos e do não cumprimento das normas que regem o tema, dá-se a criação de impactos ambientais negativos, como a disposição irregular dos mesmos em áreas de preservação permanente, terrenos e logradouros públicos. Por conseguinte, isto acaba ocasionado poluição visual, podendo gerar a proliferação de pragas e vetores de endemias, incentivando a deposição de resíduos de 
outras naturezas, a desvalorização da área ao redor e também o comprometimento da drenagem urbana.

Estudos são realizados no que se diz a respeito à criação de alternativas para eliminar o descarte dos RCD, como a reciclagem e reutilização dos mesmos, tanto pelo o que concerne a ciência dos recursos naturais finitos quanto a economia que a prática proporciona. Assim, é necessária a elaboração de opções que aliem os fatores econômicos aos ambientais, pois existem custos desde a deposição final dos resíduos em aterros quanto a potenciais gastos com remediação ambiental.

Sabe-se que os custos excessivos dos insumos para construção civil fazem com que se torne cada vez mais atrativo o investimento na reciclagem de resíduos, pois a recuperação proporciona uma significativa diminuição no custo tanto para quem os gera, como para quem adquire materiais novos. (BASTOS; CRUZ, 2016).

Contudo, antes de substituir os materiais convencionais, é importante que se tenha conhecimento sobre os materiais reciclados, para que assim haja controle de suas propriedades. Nesse sentido, pode-se verificar que os resíduos provenientes do concreto apresentam alto potencial de utilização, devido ao conhecimento de suas características básicas (Fck, idade e tipo de concreto), e, principalmente, devido ao seu menor grau de contaminação por outros materiais (matéria orgânica, plástico, borracha, insumos da construção civil) em comparação aos demais tipos de RCD, tais como os resíduos do entulho. (SANTOS et al., 2016).

No entanto, no Brasil, a reciclagem dos resíduos de construção e demolição se depara com o pré-julgamento ao seu uso posterior, em virtude à falta da criação de uma cultura do uso confiável desse material, já que o reciclado se assemelha ao natural em suas propriedades físico-químicas, não apresentando ressalvas quanto ao seu uso adequado. (BASTOS; CRUZ, 2016).

Portanto, apesar de se tratar de uma alternativa emergente, a fabricação de produtos feitos com agregados reciclados é realizada de forma tímida no país, devido ao baixo consumo do mercado, bem como a limitada tecnologia desenvolvida nesse quesito, sendo assim as suas experiências limitadas em ações das municipalidades que buscam reduzir os custos e o impacto ambiental negativo da deposição de RCD no meio urbano. Assim, mesmo a sustentabilidade ambiental ser considerada uma aliada indispensável no desenvolvimento econômico do país, a alternativa se encontra em uma ascensão a passos lentos. (ÂNGULO; ZORDAN; JOHN, 2001)

Logo, neste trabalho, optou-se por confeccionar pisos intertravados, utilizando resíduos de corpos de prova de concreto descartados após ensaio mecânico à compressão, como agregados reciclados. Assim, este estudo teve como objetivo analisar as características dos resíduos dos corpos de prova de concreto, investigando as propriedades dos agregados para a confecção de pisos intertravados e avaliando a viabilidade técnica, econômica e ambiental. 


\section{REFERENCIAL TEÓRICO}

\section{AGREGADOS RECICLADOS}

O agregado reciclado pode ser definido, segundo CONAMA (2002), como material granular proveniente do beneficiamento de resíduos de construção que apresentem características técnicas para a aplicação em obras de edificação, de infraestrutura, em aterros sanitários, ou outras obras de engenharia.

Ainda que a utilização do agregado seja uma opção em desenvolvimento, a mesma necessita se enquadrar dentro de determinados limites. De acordo com Leite (2001), para a fabricação de concreto, utilizando agregado reciclado proveniente de $\mathrm{RCD}$, é essencial que seja realizada uma caracterização sistemática, visando assim compreender satisfatoriamente o desempenho do material reciclado no seu uso em misturas de concreto, o que resultará em produtos de melhor qualidade, dessa forma, favorecendo as condições de reaproveitamento do resíduo. Desse modo, Buttler (2003) atestou em seus estudos que os resíduos de concreto, entre os demais produzidos, são os que demonstram maior potencial para reciclagem. Assim, o autor caracterizou algumas das propriedades dos resíduos de concreto, analisando a interferência do tempo transcorrido entre a moldagem e a reciclagem nas características do agregado e dos concretos. Dessa forma, a conclusão da pesquisa indicou que os resíduos reciclados colaboram, de modo positivo, para as propriedades do concreto.

Também, foi observado por Levy (2001), que a substituição gradativa de agregados naturais pelos agregados reciclados modifica as características mecânicas do concreto. Assim, o autor verificou que, a substituição de $50 \%$ dos agregados miúdos naturais pelos reciclados é ideal para algumas propriedades analisadas, como módulo de elasticidade, durabilidade, consumo de cimento e resistência mecânica.

Dentre os resultados analisados no estudo de Levy (2001), o mesmo confirmou que o incremento de resíduos de concreto até o teor de $20 \%$ não afeta o comportamento do concreto em relação ao produzido com agregados naturais, podendo ser usado sem restrições quanto à resistência mecânica e à durabilidade. Desse modo, as análises feitas pelo autor em seus estudos permitiram verificar a durabilidade de concretos gerados com os agregados reciclados quando comparados aos produzidos com agregados naturais, garantindo assim a capacidade de sua produção.

\section{PROPRIEDADES DOS AGREGADOS RECICLADOS}

As propriedades mecânicas, químicas e físicas dos agregados reciclados dependem de um conjunto de aspectos, como a composição granulométrica do agregado e o tipo de equipamento utilizado para britar o resíduo. 
Portanto, entre as características mais importantes estudadas para a aplicação do agregado reciclado em concretos estão a composição granulométrica; a trabalhabilidade e absorção de água; a massa específica e massa unitária; o material pulverulento; e a resistência à compressão. $\mathrm{O}$ estudo de todas essas propriedades para a produção de concretos deve ser considerado, pois a viabilidade técnica de sua utilização decorrerá do conhecimento absoluto do seu comportamento na estrutura de concreto. (LEITE, 2001).

\section{Composição granulométrica}

Os agregados reciclados possuem tendência a uma composição granulométrica um pouco mais grossa quando comparados aos agregados naturais, ocasionando assim um módulo de finura ligeiramente maior. Contudo, esta diferença de granulometria entre resíduos pode depender das propriedades do concreto de origem e do seu sistema de britagem. Nas usinas de reciclagem que empregam britadores de impacto são produzidos cerca de 60\% de material miúdo. (BAZUCO, 1999).

A granulometria dos agregados reciclados interfere sobre a trabalhabilidade dos concretos, sendo também um parâmetro significativo para a dosagem das misturas. (BARRA, 1996). Dessa forma, é indispensável que haja cautela quanto a composição granulométrica dos agregados reciclados, para que ocorra a produção de misturas trabalháveis com classe de compacidade aceitável, assim obtendo-se o melhor desempenho técnico e a redução dos custos do concreto produzido. (LEITE, 2001).

\section{Trabalhabilidade e Absorção de Água}

Segundo Cabral (2007), os concretos fabricados com agregados reciclados, quando comparados aos produzidos com agregados naturais, apresentam uma menor trabalhabilidade em uma mesma relação de teor de materiais secos/pasta. Esta característica pode ser explicada devido a maior absorção de água dos agregados reciclados, tornando a mistura mais seca e, assim, menos trabalhável.

Outro fator que altera a trabalhabilidade dos concretos é a textura dos agregados reciclados. De acordo com Bazuco (1999), os agregados reciclados possuem textura mais rugosa, ocorrendo assim um aumento na fricção interna, e, consequentemente, requerendo mais argamassa, para que assim obtenha-se a trabalhabilidade igual a do concreto convencional.

A velocidade de perda de abatimento do concreto feito com agregados reciclados é maior do que o concreto produzido com agregados naturais. Machado Jr, Latterza e Mendes (1998) atestam que, quando todos os agregados são substituídos por reciclados, a alta absorção e o maior índice de vazios aumentam a velocidade de perda de abatimento, tendo-se trabalhabilidade durante, apenas, 60 minutos. 
Devido os agregados reciclados apresentarem alta porosidade, diversos autores realizaram seus estudos com misturas de concreto que variavam a quantidade de água, para que dessa forma o ensaio de abatimento, e assim consequentemente, a trabalhabilidade do mesmo fossem satisfeitos. Porém, dessa forma a relação a/c é alterada, fazendo com que a classe de resistência do mesmo acabe diminuindo. (VIEIRA; MOLIN, 2004)

Apesar da ocorrência da alta porosidade dos agregados reciclados, GómezSoberón (2002) afirma em seus estudos que a utilização de tais agregados em concretos é possível, e Zaharieva, et al. (2002) alegam que a modificação na relação a/c para obter-se o abatimento desejado diminui a resistência, mas que o acréscimo de água na mistura se faz necessária para que se atinja a trabalhabilidade adequada.

\section{Massa Específica e Massa Unitária}

Em geral os agregados reciclados apresentam uma massa específica e uma massa unitária menor do que os agregados naturais. Visto que, para a massa específica essa redução ocorre devido as características da matéria prima empregada, pois são menos densas que os agregados naturais. Já para a massa unitária, além da redução devido a densidade do material e a alta porosidade dos agregados reciclados, a forma irregular das partículas dos agregados colabora para a redução da mesma. Em contrapartida, essas reduções também estão relacionadas a granulometria dos agregados reciclados. (CABRAL, 2007).

\section{Material Pulverulento}

A resistência mecânica dos concretos depende diretamente da granulometria, tensão de ruptura e da resistência de ligação entre a pasta e a superfície do agregado usado em sua composição. Desse modo, o material pulverulento pode influenciar consideravelmente a quantidade de água necessária ao amassamento, e, assim, promover uma diminuição da resistência mecânica do concreto a ser produzido. Além disso, o material pulverulento pode diminuir a resistência ao desgaste do concreto, principalmente por abrasão. (COUTINHO, 1997).

\section{Resistência à Compressão}

De modo geral, os materiais que compõem o concreto influenciam diretamente a sua resistência mecânica e o seu desempenho final. Além disso, os agregados também são indispensáveis para uma análise criteriosa das propriedades do concreto, inclusive quando é utilizado agregados reciclados com o teor de substituição de até $80 \%$ da mistura. (LEITE, 2001). 
Tavakoli e Soroushian (1996) atestam em seus estudos que se a resistência à compressão do concreto original que será então reciclado for maior que a do concreto de referência com agregados naturais, o concreto de agregados reciclados poderá ser feito para obter uma resistência à compressão maior do que a do concreto de referência.

Santos, et al. (2016) desenvolveram um estudo da utilização de resíduos de corpos de prova em substituição ao agregado graúdo em concretos, e atestaram que é válida a sua utilização. No trabalho verificou-se que quanto maior o teor de agregado graúdo reciclado adicionado na mistura, menor é o índice de vazios, ocorrendo dessa forma um maior empacotamento da mistura, gerando assim uma maior compacidade, e, quanto maior a compacidade, maior os níveis de resistência à compressão. Assim, seu trabalho apresentou uma resistência mecânica simples, seguindo as recomendações da ABNT/NBR 5739 (2007), com uma média de 71,88MPa, as rupturas foram realizadas aos 7 e 28 dias de cura, e para o ensaio foi utilizada prensa elétrica digital, com velocidade controlada e capacidade de 100 toneladas.

\section{PAVIMENTO INTERTRAVADO}

O piso intertravado de concreto passou a ser muito usado na construção de pavimentos devido a sua versatilidade e simplicidade de aplicação. Além disso, destacase devido a sua fácil execução e rápida capacitação de mão de obra, bem como a não necessidade de equipamentos específicos, possibilitando o emprego de mão de obra local, obtendo-se assim economia no tempo de construção e uso imediato após sua execução. (SIMIELI et al., 2007).

Pode-se destacar outras vantagens na utilização de pavimento intertravado de concreto $\mathrm{ABCP}$ (2002):

- Impossibilitam a propagação de trincas da camada de base para a face superior do pavimento.

- Possibilita simples acesso às instalações de serviços subterrâneos, devido as peças de concreto serem facilmente reparadas, podendo ser também reutilizadas.

- Demonstra ampla eficácia estrutural, durabilidade e resistência à abrasão por serem de alta qualidade, resistem ao escoamento de óleos e ao despejo de combustíveis, atribuindo maior valor paisagístico e elevada visibilidade, independentemente de sua coloração, não tendo diferenciação quanto iluminação natural ou artificial.

- $\quad$ Proporciona a micro drenagem, por ser o pavimento mais permeável atualmente. 
Pode-se citar como outra vantagem da utilização de pisos intertravados o conforto térmico, que segundo ABCP (2009), a coloração mais clara das peças de concreto reduz a absorção de calor na superfície do pavimento, assim diminuindo a formação de ilhas de calor nos centros urbanos.

O pavimento também oferece a capacidade de poupar energia elétrica devido a sua capacidade de aumentar em 30\% a reflexão da luz através de sua coloração clara, se comparado ao pavimento flexível, assim, permitindo uma economia de 40\% no consumo de energia na iluminação pública. (ABCP, 2011).

No mais, o piso intertravado possui uma construção simples, onde são assentados os blocos sob uma camada de areia grossa, em seguida, compactam-se o mesmo, e então espalha-se areia fina a fim de preencher as juntas e, assim, realizase a compactação novamente, até que estas sejam completamente preenchidas. Dessa forma, o intertravamento dos pisos é concluído, o que promove resistência aos mesmos, diferenciando-os dos demais.

Em relação as propriedades mecânicas, a norma ABNT/NBR 9781 (1987b) estabelece que a resistência necessária à compressão das peças, prevista de acordo com a ABNT/NBR-9780 (1987a), deve ser de 35 MPa para tráfego de pedestres, veículos leves e veículos comerciais de linha, ou de $50 \mathrm{MPa}$ quando houver tráfego de veículos especiais e solicitações capazes de produzir efeitos de abrasão acentuados.

\section{METODOLOGIA}

O procedimento experimental empregado para analisar as características dos resíduos de corpos de prova de concreto descartados, após ensaio mecânico à compressão, para confecção de pavimentação intertravada foi constituído das etapas: britagem dos corpos de prova e obtenção do agregado reciclado, planejamento e realização de ensaios, realização de cálculo de traços, dosagem experimental dos pisos intertravados e análise dos resultados obtidos.

Os agregados reciclados utilizados neste estudo, provenientes de resíduos de corpos de prova de concreto descartados, após ensaio mecânico à compressão, foram obtidos a partir da coleta de amostras na empresa prestadora de serviços de concretagem, POLIMIX, em São João da Boa Vista/SP.

Inicialmente, um total de 60 amostras foram pré-selecionadas e coletadas, in loco, sendo escolhidas apenas corpos de prova que, após o ensaio de compressão até a ruptura, demostraram níveis de resistências entre 25 a $35 \mathrm{MPa}$.

Em seguida as amostras coletadas passaram por um processo de britagem (britador de impacto, da linha de reciclagem de entulho), e depois o material foi direcionado para a moagem (moinho RGM 250). Estes equipamentos e o processo de britagem do material desta pesquisa foram fornecidos e realizados pela empresa $\mathrm{RG}$ MAQ de Piracicaba/SP, e assim foi obtido $205 \mathrm{Kg}$ de agregado reciclado de concreto. 
Após realizar a trituração dos resíduos, os mesmos foram separados em duas granulometrias, uma para obter o agregado miúdo reciclado (AMR) e outra para se obter o agregado graúdo reciclado (AGR), ambos usados nos traços dos concretos.

Devido ao agregado reciclado apresentar uma alta taxa de absorção de água, foi necessário incorporar o aditivo superplastificante Maximent PXT 72, para que ocorresse a redução na relação água/cimento, e, assim, não ocasionasse maiores problemas no abatimento e moldabilidade do concreto.

O traço padrão com resistência mínima de $35 \mathrm{MPa}$, como dita a ABNT/NBR 9781 (1967b), foi calculado adotando-se o método de dosagem do concreto publicado por Rodrigues (1998). Dessa forma, foi definido o traço 1:1,46:1,25:0,45, com 0,8\% de aditivo e com faixa de consistência variando de $90 \pm 10 \mathrm{~mm}$. Já nos traços secundários, foram feitas substituições do agregado natural pelo reciclado em percentagens de $20 \%$, $40 \%, 60 \%, 80 \%$ e $100 \%$, em relação a massa. Os quadros 1 e 2 apresentam os traços estudados.

Quadro 1: Traços Estudados - Agregado Miúdo Reciclado

Quadro 2: Traços Estudados - Agregado Graúdo Reciclado

\begin{tabular}{|c|c|}
\hline $\begin{array}{c}\text { Teor de Substituição } \\
(\%)\end{array}$ & $\begin{array}{c}\text { Traço } \\
\text { 1:AMN:AMR:AGN:AG }\end{array}$ \\
\hline 0 & $1: 1,46: 0,00: 1,25: 0,45$ \\
\hline 20 & $1: 1,17: 0,10: 1,25: 0,45$ \\
\hline 40 & $1: 0,88: 0,20: 1,25: 0,45$ \\
\hline 60 & $1: 0,58: 0,30: 1,25: 0,45$ \\
\hline 80 & $1: 0,29: 0,40: 1,25: 0,45$ \\
\hline 100 & $1: 0,00: 0,50: 1,25: 0,45$ \\
\hline
\end{tabular}

\begin{tabular}{|c|c|}
\hline $\begin{array}{c}\text { Teor de Substituição } \\
\text { (\%) }\end{array}$ & $\begin{array}{c}\text { Traço } \\
\text { 1:AMN:AGN:AGR:AG }\end{array}$ \\
\hline 0 & $1: 1,46: 1,25: 0,00: 0,45$ \\
\hline 20 & $1: 1,46: 0,99: 0,20: 0,45$ \\
\hline 40 & $1: 1,46: 0,75: 0,40: 0,45$ \\
\hline 60 & $1: 1,46: 0,50: 0,61: 0,45$ \\
\hline 80 & $1: 1,46: 0,25: 0,82: 0,45$ \\
\hline 100 & $1: 1,46: 0,00: 1,02: 0,45$ \\
\hline
\end{tabular}

Logo após a definição dos traços foram realizados ensaios de composição granulométrica dos agregados miúdos e graúdos, ABNT/NBR NM 248 (2003) e ABNT/NBR 7211 (2005), massa unitária, ABNT/NBR 7251 (1982) e para determinação do material pulverulento, ABNT/NBR NM 46 (2001). Para os agregados miúdos também se realizou ensaios de absorção de água, ABNT/NBR NM 30 (2000) e de massa específica, ABNT/NBR NM 52 (2002), e com o agregado graúdo foram feitos ensaios de determinação da massa específica aparente e absorção, ABNT/NBR NM 53 (2002).

Posteriormente, foram confeccionados 03 corpos de prova de $10 \times 20 \mathrm{~cm}$ de cada dosagem estudada, resultando em um total de 33 corpos de prova, e, posterirormente, realizados ensaios de compressão nas idades de 7, 14 e 28 dias. Os corpos de prova foram moldados em formas metálicas e adensados manualmente em duas camadas de 12 golpes cada e desmoldados após 24 horas. Após a desforma foram submetidos a cura por imersão em água até completar as idades de ruptura. (ABNT/NBR 5738, 2015).

Os materiais utilizados na elaboração do traço de concreto foram os seguintes: 
- Aglomerante: cimento CP - V ARI, por se tratar de um cimento que possui alta reatividade na aplicação em suas primeiras horas, assim apresentando uma alta resistência nos primeiros dias de sua aplicação.

- Água: foi utilizada água de uso comum fornecida pela SABESP Companhia de Saneamento Básico do Estado de São Paulo na cidade de São João da Boa Vista - Laboratório de materiais do curso de Engenharia Civil UNIFAE/CETEP.

- Agregados: utilizou-se agregado graúdo (pedrisco) com diâmetro entre 4,8 $\mathrm{mm}$ a 9,5 mm, e agregado miúdo (areia grossa) com diâmetro máximo de $4,75 \mathrm{~mm}$.

- Resíduo: foi utilizado resíduos provenientes da britagem de corpos de prova de concreto descartados após ensaio mecânico de compressão.

Por fim, quando completada as idades de ruptura, os corpos de prova em estado endurecido foram planeados, utilizando uma retificadora manual, e em seguida submetidos a teste de resistência à compressão no laboratório da empresa prestadora de serviços de concretagem, POLIMIX, em São João da Boa Vista/SP, segundo descrito na ABNT/NBR 5739 (1994).

\section{RESULTADOS E DISCUSSÕES}

A Tabela 3 apresenta resultado dos ensaios de composição granulométrica dos agregados miúdo e graúdo. Nota-se que o agregado miúdo, tanto o natural quanto o reciclado são areias grossas, pois estas são aquelas que passam na peneira de 4,8 mm e ficam retidas na peneira de $1,2 \mathrm{~mm}$, e, como a areia natural apresenta diâmetro máximo de 4,75 mm e a areia reciclada de $2,36 \mathrm{~mm}$ as mesmas são classificadas como tal.

O agregado reciclado, como mostrado no Quadro 3, apresenta uma taxa de absorção de água mais elevada quando comparado com o agregado convencional. Também, pode-se observar que o agregado reciclado possui uma massa específica menor do que o agregado natural, apresentando uma diferença mais evidente o agregado miúdo. O material pulverulento também apresentou uma alteração significativa quando comparados os agregados reciclados aos convencionais, sendo os reciclados com maior teor de material pulverulento. 
Quadro 3: Características Físicas dos agregados

\begin{tabular}{|c|c|c|c|c|c|c|c|c|c|}
\hline \multirow{3}{*}{ Agregado } & \multirow{3}{*}{$\begin{array}{c}\text { б } \\
\text { máximo } \\
\text { (mm) }\end{array}$} & \multirow{3}{*}{$\begin{array}{c}\text { Módulo } \\
\text { de Finura }\end{array}$} & \multicolumn{3}{|c|}{ Massa Específica } & \multirow{3}{*}{$\begin{array}{c}\text { Absorção } \\
(\%)\end{array}$} & \multirow{3}{*}{$\begin{array}{c}\text { Material } \\
\text { Pulverulento } \\
(\%)\end{array}$} & \multicolumn{2}{|c|}{ Massa Unitária } \\
\hline & & & $\begin{array}{c}\text { Saturado } \\
\text { Superfície } \\
\text { Seca } \\
\end{array}$ & Seca & Aparente & & & \multirow[t]{2}{*}{$\begin{array}{c}\text { Solta } \\
\left(\mathrm{Kg} / \mathbf{d m}^{3}\right)\end{array}$} & \multirow[t]{2}{*}{$\begin{array}{c}\text { Compactada } \\
\left(\mathrm{Kg} / \mathbf{d m}^{3}\right)\end{array}$} \\
\hline & & & & $/ \mathrm{cm}^{3}$ & & & & & \\
\hline $\begin{array}{c}\text { Pedrisco } \\
\text { Natural }\end{array}$ & 9,5 & 2,06 & 2,64 & 2,58 & 2,75 & 2,33 & 1,6 & 0,96 & 1,01 \\
\hline $\begin{array}{l}\text { Pedrisco } \\
\text { Reciclado }\end{array}$ & 12,5 & 2,83 & 2,39 & 2,28 & 2,58 & 5,17 & 3,2 & 0,92 & 0,95 \\
\hline $\begin{array}{c}\text { Areia } \\
\text { Natural }\end{array}$ & 4,75 & 3,75 & 2,31 & 2,39 & 2,26 & 2,25 & 2,4 & 1,02 & - \\
\hline $\begin{array}{c}\text { Areia } \\
\text { Reciclada }\end{array}$ & 2,36 & 3,49 & 0,69 & 0,67 & 0,63 & 8,93 & 8,5 & 1,01 & - \\
\hline
\end{tabular}

As Figuras 1 e 2 apresentam as curvas granulométricas dos agregados reciclados e naturais. Observa-se que na Figura 2 a curva apresenta alta declividade, aproximando-se da vertical, isso indica que o agregado miúdo é uniforme, onde a maioria dos grãos apresentam, aproximadamente, a mesma dimensão. A uniformidade dos materiais é caracterizada pelo coeficiente de uniformidade $(\mathrm{Cu})$, este representa a inclinação média da curva entre 10 e 60\% de material passante, e o valor máximo que pode assumir é igual a 1, correspondente a um material perfeitamente uniforme, com todas as partículas iguais. No caso da Figura 2 o $\mathrm{Cu}$ apresentou um valor de 0,71, demonstrando ser um material uniforme. Já na Figura 1 verifica-se que a curva é suave apresentando uma concavidade, sendo assim classificada como um material bem graduado, onde as partículas abrangem uma extensa faixa de dimensões. Dessa forma, a distribuição granulométrica pode ser definida pela sua curvatura, ou seja, pelo coeficiente de curvatura $(\mathrm{Cc})$, onde são considerados bem graduados os agregados graúdos que apresentem valores menores que 3 e maiores que 1. No caso da Figura 1 o Cc é de 1,20, considerado material bem graduado.

Figura 1: Curva Granulométrica - Agregado Miúdo

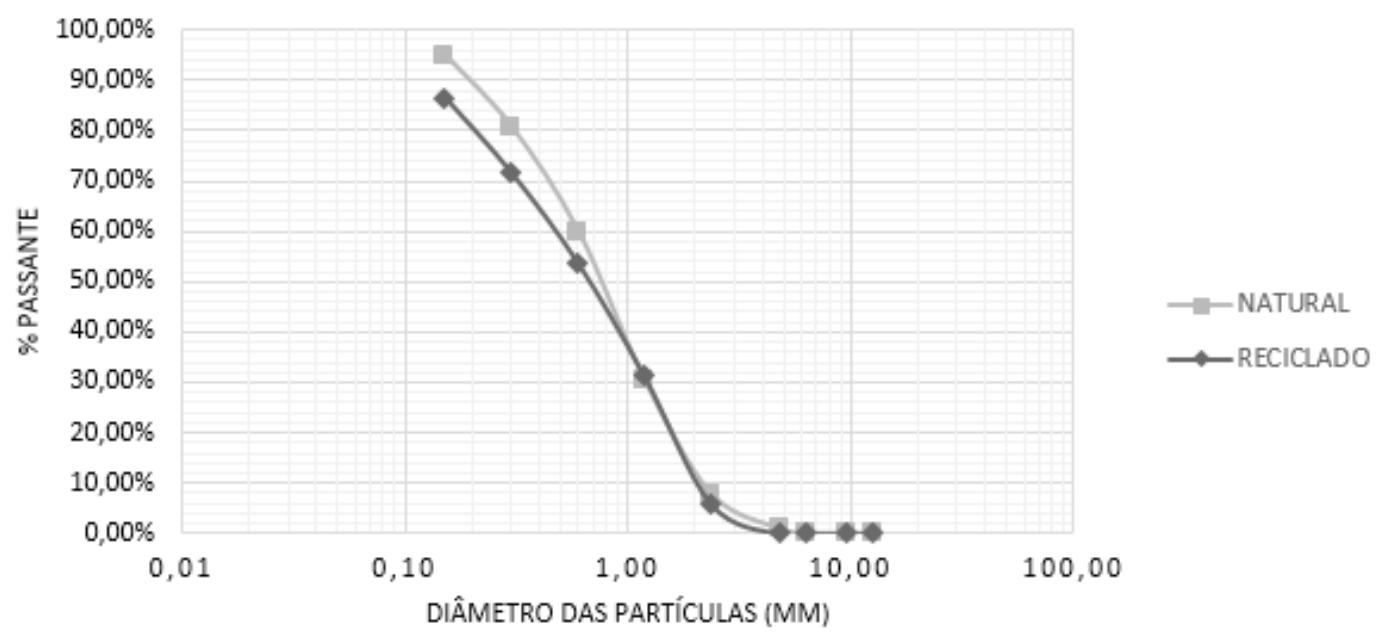


Figura 2: Curva Granulométrica - Agregado Graúdo

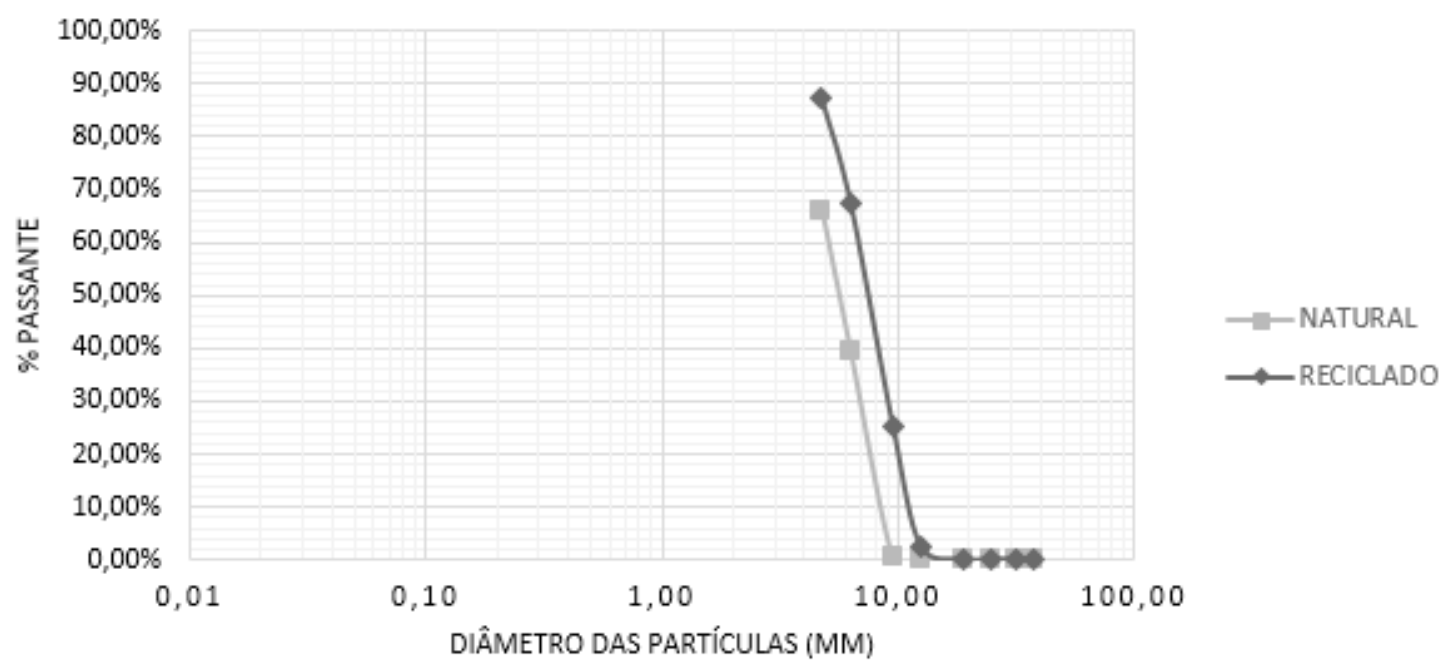

No ensaio de resistência à compressão, obteve-se a tensão máxima que cada corpo de prova foi submetido, em megapascal ( $\mathrm{MPa}$ ), logo antes do rompimento. Os resultados estão demonstrados nas Figuras 3 e 4.

Nota-se que, aos 7 e 28 dias de cura, todas as dosagens estudadas apresentaram níveis de resistência iguais ou acima do especificado pela ABNT/NBR 9781 (1987b), que é de $35 \mathrm{MPa}$ para tráfego de pedestres, veículos leves e veículos comerciais de linha. Aos 14 dias de cura os níveis de resistência também foram satisfatórios, tendo resultados acima de $35 \mathrm{MPa}$, exceto para a dosagem com $80 \%$ de substituição de agregados graúdos, com resistência de 32,2 $\mathrm{MPa}$, que não atingiu a resistência especificada pela norma. A maior resistência à compressão foi obtida no $28^{\circ}$ dia, para a dosagem com 60\% de substituição dos agregados graúdos naturais, com 43,3 Mpa.

De acordo com as Figuras 3 e 4, é possível observar que quando comparados os 7 e 14 dias de cura, nos casos em que a substituição do agregado convencional pelo reciclado foi de $20 \%$ de AMR, e de $40 \%$ e $80 \%$ de AGR, houve redução da resistência, e, já nas dosagens com 40\%, 60\%, 80\% e 100\% de AMR, e nas de $20 \%, 60 \%$ e $100 \%$ de AGR, houve aumento dessa mesma propriedade. Além disso, pode-se notar que a melhor resistência à compressão é obtida com a percentagem de $60 \%$ de substituição, tanto para o AMR, quanto para o AGR. 
Figura 3: Resistência à Compressão - Agregado Miúdo Reciclado (AMR)
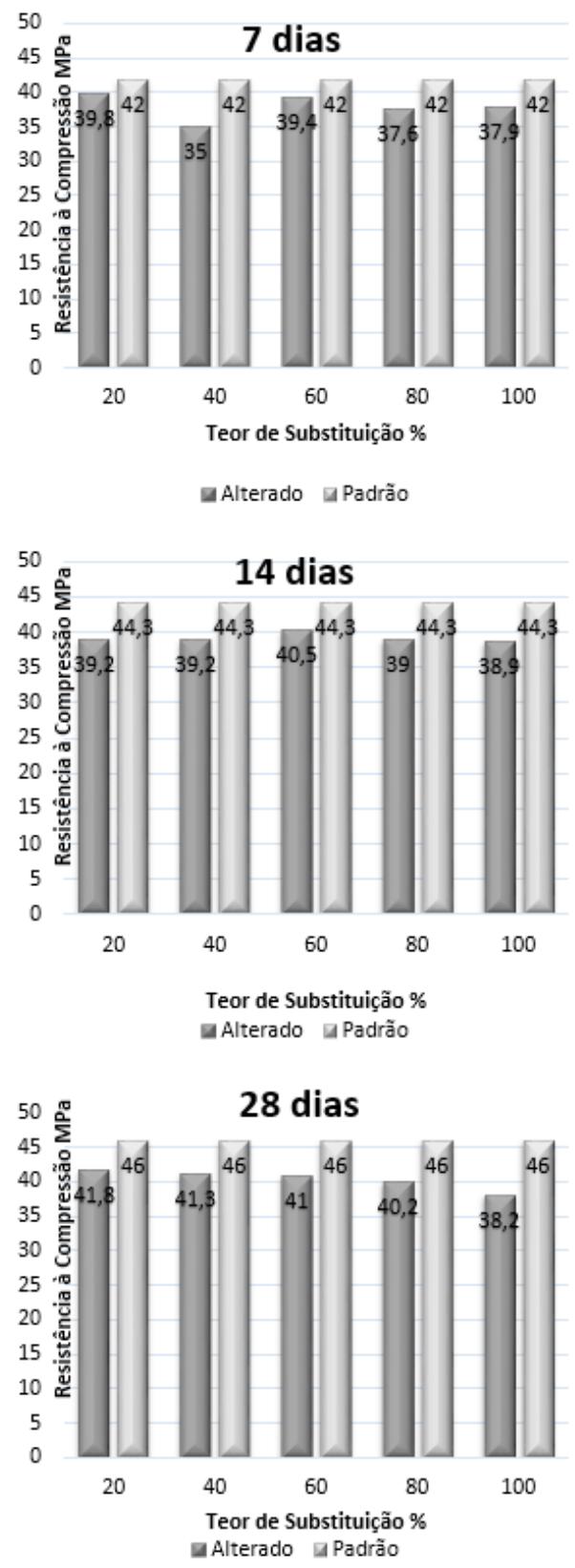

Figura 4: Resistência à Compressão - Agregado Graúdo Reciclado (AGR)
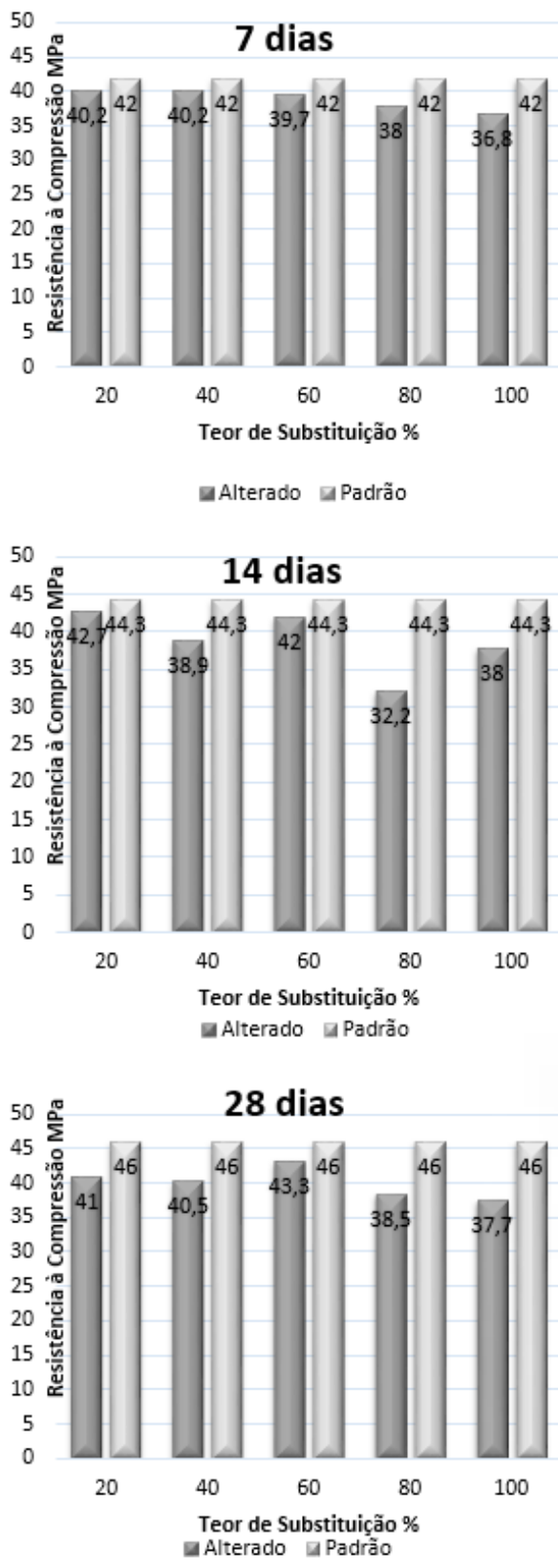

Por meio do ensaio de absorção de água, como mostra o Quadro 4, verifica-se que o índice de absorção está em conformidade com a ABNT/NBR 9781 (1987b) para os corpos de prova com teor de substituição de 0\%, 20\%, 40\%, 60\% e 100\%. Já para uma dosagem com $80 \%$ de índice de substituição o mesmo não apresenta conformidade com a norma citada, pois esta adota como limite $\leq 7 \%$ de absorção de água dos valores individuais. 
Quadro 4: Absorção de Água Individual aos 28 dias

\begin{tabular}{|c|c|c|}
\hline \multirow{2}{*}{ Teor de Substituição (\%) } & \multicolumn{2}{|c|}{ Absorção de Água (\%) } \\
\cline { 2 - 3 } & AMR & AGR \\
\hline $\mathbf{0}$ & 6,7 & 6,7 \\
\hline $\mathbf{2 0}$ & 5,5 & 6,11 \\
\hline $\mathbf{4 0}$ & 6,73 & 6,67 \\
\hline $\mathbf{6 0}$ & 5,7 & 6,94 \\
\hline $\mathbf{8 0}$ & 6,83 & 7,33 \\
\hline $\mathbf{1 0 0}$ & 6,03 & 6,5 \\
\hline
\end{tabular}

Para a análise de viabilidade econômica baseou-se na tabela CPOS (2018), onde o valor para fabricação de $1 \mathrm{~m}^{2}$ de piso intertravado, utilizando-se material natural, é de $\mathrm{R} \$ 39,87$ para o bloco de $80 \mathrm{~mm}$ de altura. Já para o piso com substituição de $100 \%$ do agregado graúdo, foi calculado, neste estudo, um custo de $\mathrm{R} \$ 30,96$. Tal custo foi composto por $\mathrm{R} \$ 32,23$ de cimento; $\mathrm{R} \$ 5,22$ de areia; $\mathrm{R} \$ 0,07$ de água; $\mathrm{R} \$ 0,62$ de aditivo; $\mathrm{R} \$ 0,21$ de resíduos de corpo de prova; $\mathrm{R} \$ 0,46$ de energia elétrica; e subtraído $\mathrm{R} \$ 7,85$ (relativos ao custo do armazenamento em aterro de inertes), chegando-se ao valor de $\mathrm{R}$ \$30,96. Portanto, utilizando-se material reciclável tem-se uma redução no custo de fabricação de piso intertravado de aproximadamente $22,35 \%$.

Para determinar o valor econômico do piso intertravado reciclado foi desconsiderado o valor unitário do maquinário utilizado para triturar os resíduos de corpo de prova, uma vez que o mesmo seria parte de um conjunto de investimentos iniciais da empresa fabricante deste produto. Além disso, foi considerado que a matéria prima possui valor negativo, não apresentando custo para sua obtenção, isso ocorre, pois, ela teria um custo de destinação de resíduo sólido em aterro de inertes, se fosse descartada, o que não acontecerá mais através da sua reutilização para fabricação de pisos intertravados, atingindo assim a sua equivalência. Também, a mão de obra foi descartada pois esta seria equivalente a mão de obra empregada para depositar o resíduo em aterro de inertes.

Assim, para as empresas, a aquisição de um triturador de matéria prima é viável, ou até mesmo o aluguel desta, pois esta apresenta uma maior praticidade e velocidade para se obter o resíduo do agregado reciclado. $\mathrm{O}$ valor de mercado, fornecido pela empresa RG MAQ, das máquinas (alimentador, britador de impacto, duas esteiras transportadoras e moinho) necessárias para se obter a granulometria desejada é de $\mathrm{R} \$$ 150.000,00, apresentando uma capacidade de 10 toneladas/hora, em estado de eficiência máxima de produção, sendo que o valor da mesma poderá ser amortizado em dois anos, através da economia de produção que o piso reciclado apresenta. 


\section{CONSIDERAÇÕES FINAIS}

Os resultados obtidos nesta pesquisa foram satisfatórios, visto que atenderam aos propósitos previamente estabelecidos de minimizar os gastos orçamentários de produção do piso intertravado e de reduzir os impactos ambientais, obedecendo aos requisitos solicitados pela ABNT/NBR 9781 (1987b).

Este trabalho avaliou o uso de concreto de consistência plástica, oportunizando o uso de fôrmas de plástico em sua confecção, assim não havendo a necessidade de utilização das vibro prensas para a compactação das peças. A utilização das fôrmas de plástico tem por intuito facilitar o processo de fabricação das peças pré-moldadas de concreto, tornando-se uma alternativa viável para produção em pequena escala, em empresas e prefeituras que não possuem recursos para compra de equipamentos específicos.

Dessa forma, as peças obtidas apresentaram ótimo acabamento, proporcionando a execução de um pavimento de qualidade memorável e com arquitetura agradável, sendo assim ideal para calçadas, pavimentação residencial e espaços urbanos.

Os resultados mostram que aos 28 dias todas as percentagens de substituição são viáveis, apresentando níveis de resistência em percentagens de $100 \%$ de $38,2 \mathrm{MPa}$ e 37,7 MPa, para agregados miúdos reciclados e graúdos reciclados, respectivamente. Também o critério de absorção de água é atendido, conforme exigido pela ABNT/NBR 9781 (1987b).

Quando analisado os quesitos técnicos, ambientais e econômicos, confirmase que o melhor índice de substituição é o de 100\% de agregado reciclado, tanto para graúdo quanto para miúdo, apresentando níveis de resistência acima dos $35 \mathrm{MPa}$, exigidos pela norma ABNT/NBR 9781 (1987b). Além dos ganhos ambientais, já que o mesmo não será mais descartado, sendo reaproveitado $100 \%$ do resíduo na produção dos pisos, assim, gerando uma redução de aproximadamente de 22,35\% no processo de fabricação dos pisos.

Assim, é possível afirmar que a produção de pisos intertravados reciclados para tráfego de pedestres, veículos leves e veículos comerciais de linha é uma alternativa ambiental e economicamente viável, sendo executada de forma simples, eficaz e de baixo custo.

\section{REFERÊNCIAS}

ÂNGUlO, S. C.; ZORDAN, S. E.; JOHN, V. M. Desenvolvimento sustentável e a reciclagem de resíduos na construção civil. PCC - São Paulo. 2001. 13 f. Departamento Engenharia de Construção Civil da Escola Politécnica.

\footnotetext{
ABCP - ASSOCIAÇÃO BRASILEIRA DE CIMENTO PORTLAND. Manual Técnico para Implementação da Habitação 10. São Paulo,2002.
} 
ABCP - ASSOCIAÇÃO BRASILEIRA DE CIMENTO PORTLAND. Pavimento Intertravado, São Paulo, dez. 2009. Disponível em: <http://www.abcp.org.br/cms/ basico-sobre-cimento/aplicacoes/pavimento-intertravado/ $>$

ABCP - ASSOCIAÇÃO BRASILEIRA DE CIMENTO PORTLAND. Pavimento Intertravado é alternativa sustentável para economia de recursos, São Paulo, ago. 2011. Disponível em <http://www.abcp.org.br/cms/imprensa/banco-de-pautas/ pavimento-intertravado-e-alternativa-sustentavel-para-economia-de-recursos $/>$

ABRECON - ASSOCIAÇÃO BRASILEIRA PARA RECICLAGEM DE RESÍDUOS DA CONSTRUÇÃO CIVIL E DEMOLIÇÃO. Resíduos da construção e demolição: geração de emprego e renda, São Paulo, out. 2016. Disponível em: <http://abrecon. org.br/residuos-da-construcao-e-demolicao-geracao-de-emprego-e-renda/ >

ABNT - ASSOCIAÇÃO BRASILEIRA DE NORMAS TÉCNICAS: NBR-9780. Peças de concreto para pavimentação, determinação da resistência à compressão. Rio de Janeiro, 1987a.

NBR-9781. Peças de concreto para pavimentação, especificação. Rio de Janeiro, 1987b.

. NBR- NM 248.Agregados - Determinação da composição granulométrica. Rio de Janeiro, 2003.

. NBR-721 1.Agregados para concreto - Especificação. Rio de Janeiro, 2005.

. NBR- 725 1.Agregado em estado solto - Determinação da massa unitária. Rio de Janeiro, 1982.

. NBR- NM 30. Agregado miúdo - Determinação da absorção de água. Rio de Janeiro, 2000.

NBR- NM 46. Agregados - Determinação do material fino que passa através da peneira $75 \mu \mathrm{m}$, por lavagem. Rio de Janeiro, 2001.

NBR- NM 52. Agregado miúdo - Determinação da massa específica e massa específica aparente. Rio de Janeiro, 2002.

. NBR- NM 53. Agregado graúdo - Determinação de massa específica, massa específica aparente e absorção de água. Rio de Janeiro, 2002.

NBR- 5738.Concreto - Procedimento para moldagem e cura de corpos de prova. Rio de Janeiro, 2015. 
. NBR- 5739.Concreto - Ensaio de compressão de corpos de prova cilíndricos. Rio de Janeiro, 1994.

. NBR- 5739.Concreto - Ensaio de compressão de corpos de prova cilíndricos. Rio de Janeiro, 2007.

BARRA, M. Estudio de la durabilidad del hormigón de árido reciclado en su aplicación como hormigón armado. Barcelona, 1996. 222p. Tese (Doutorado) Universidade Politécnica da Catalunya.

BASTOS, I. A.; CRUZ, L. F. Fabricação de blocos de concreto para vedação com o uso de agregados reciclados em canteiro de obras. Vitória, ES, 2016.

BAZUCO, R. S. Utilização de agregados reciclados de concreto para produção de novos concretos. Florianópolis, SC, 1999.

BRASILEIRO, L. L.; MATOS, J. M. E. Revisão Bibliográfica: reutilização de resíduos da construção e demolição na indústria da construção civil. Teresina, PI, 2015.

BUTTLER, A. M. Concreto com agregados graúdos reciclados de concreto influência da idade de reciclagem nas propriedades dos agregados e concretos reciclados. São Carlos, SP, 2003.

CABRAL, A. E. B. Modelagem de propriedades mecânicas e de durabilidade de concretos produzidos com agregados reciclados, considerando-se a variabilidade da composição do RCD. Tese apresentada a escola de engenharia de São Carlos, como parte dos requisitos para obtenção do título de doutor em ciência da engenharia ambiental, 2007.

CONAMA - CONSELHO NACIONAL DO MEIO AMBIENTE. Resolução $\mathbf{n}^{\mathbf{0}}$ 307, de 05 de julho de 2002: Estabelece diretrizes, critérios e procedimentos para a gestão dos resíduos da construção civil. Diário Oficial [da] República Federativa do Brasil, Brasília, DF, 17 jul. 2002.

COUTINHO, A. S. Fabrico e propriedades do betão. 3. ed. Lisboa: Laboratório Nacional de Engenharia Civil, 1997. 3v. v.1. $401 \mathrm{p}$.

CPOS - COMPANIA PAULISTA DE OBRAS E SERVIÇOS. Relatório de Insumos, versão 173 de 02 julho de 2018.

GÓMEZ-SOBERÓN, J.M.V. Porosity of concrete with substitution of recycled concrete aggregate: an experimental study. Cement and concrete research, 2002. 
LEI FEDERAL N ${ }^{\circ}$ 12.305. Institui a Política Nacional de Resíduos Sólidos e dá outras providências, 02 de agosto de 2010. Disponível em: <http://www.planalto. gov.br/ccivil_03/_ato2007-2010/2010/lei/112305.htm.

LEITE, M. B. Avaliação de propriedades mecânicas de concretos produzidos com agregados reciclados de resíduos de construção e demolição. Porto Alegre, RS, 2001.

LEVY, S.M. Contribuição ao estudo da durabilidade de concretos produzidos com resíduos de concreto e alvenaria. São Paulo, 2001.

MACHADO JR. E. F.; LATTERZA, L. M.; MENDES, C. L. Influência do Agregado Graúdo, Proveniente da Reciclagem de Rejeitos de Construção e Demolição (entulho), na Perda do Abatimento do Concreto Fresco e nas Propriedades Mecânicas do Concreto Endurecido. Anais da Reunião do IBRACON, Rio de Janeiro, 1998.

RODRIGUES, P. P. F. Parâmetros de Dosagem do Concreto. ET-67. 3 ed. São Paulo: IBRACON-Associação Brasileira de Cimento Portland, 1998.

SANTOS, S. B. J. S. et al. Utilização de resíduos de corpos de prova em substituição do agregado graúdo de concretos. Revista InterScientia, dez. 2016. Disponível em: $<$ https://periodicos.unipe.br/index.php/interscientia/article/view/524>. Acesso em: 06 de maio 2018.

SIMIELI, D. et al. Utilização de Agregados Reciclados em Pavimentos Intertravados. Revista Exata. Centro Universitário Nove de Julho. São Paulo, 2007.

TAVAKOLI, M.; SOROUSHIAN, P. Strengths of Recycled Aggregate Concrete Made Using Field-Demolished Concrete as Aggregate. ACI Materials Journal, v. 93, n $^{\circ}$ 2, 1996. pp. 182-190.

VIEIRA, G. L.; MOLIN, D. C. C. Viabilidade técnica da utilização de concretos com agregados reciclados de resíduos de construção e demolição. Ambiente Construído, Porto Alegre, Rio Grande do Sul, 2004.

ZAHARIEVA, R. et al. Assessment of the surface permeation properties of recycled aggregate concrete. Cement \& Concrete Composites, 2002. 